\title{
Morality and values in support of universal healthcare must be enshrined in law Comment on "Morality and Markets in the NHS"
}

\author{
Allyson M Pollock*
}

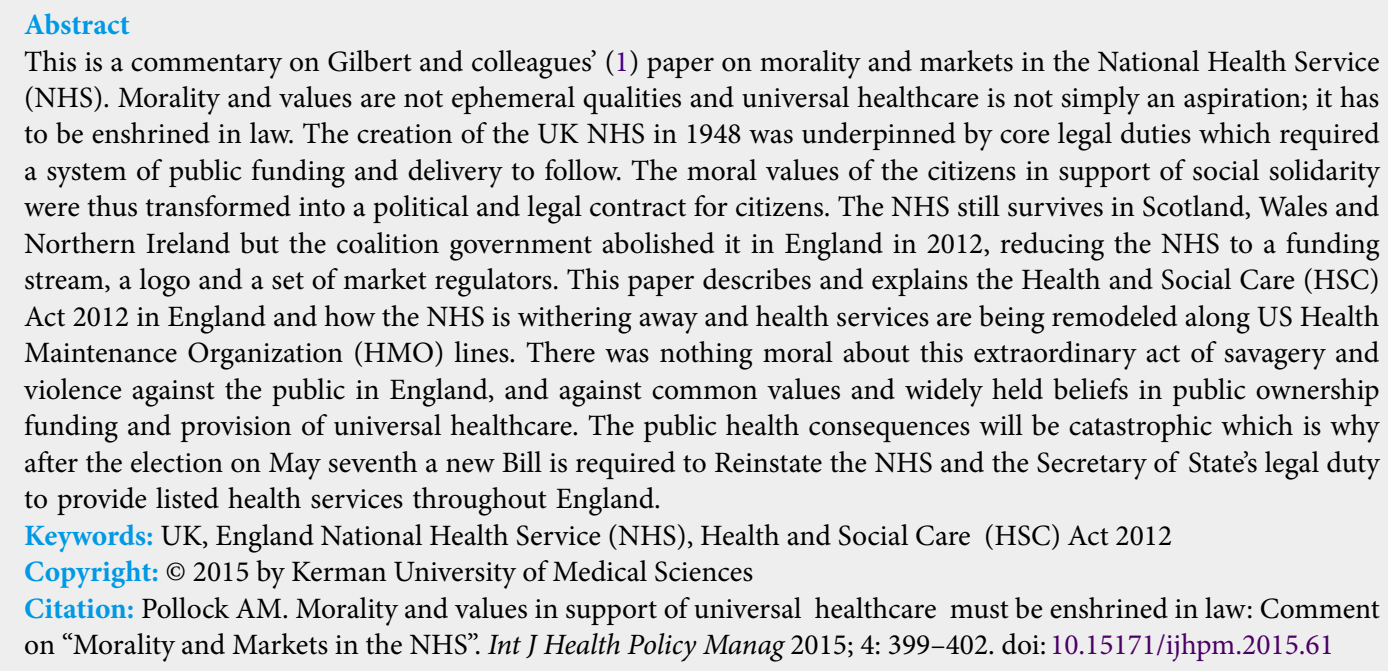

This is a commentary on Gilbert and colleagues' (1) paper on morality and markets in the National Health Service (NHS). Morality and values are not ephemeral qualities and universal healthcare is not simply an aspiration; it has to be enshrined in law. The creation of the UK NHS in 1948 was underpinned by core legal duties which required a system of public funding and delivery to follow. The moral values of the citizens in support of social solidarity were thus transformed into a political and legal contract for citizens. The NHS still survives in Scotland, Wales and Northern Ireland but the coalition government abolished it in England in 2012, reducing the NHS to a funding stream, a logo and a set of market regulators. This paper describes and explains the Health and Social Care (HSC) Act 2012 in England and how the NHS is withering away and health services are being remodeled along US Health Maintenance Organization (HMO) lines. There was nothing moral about this extraordinary act of savagery and violence against the public in England, and against common values and widely held beliefs in public ownership funding and provision of universal healthcare. The public health consequences will be catastrophic which is why after the election on May seventh a new Bill is required to Reinstate the NHS and the Secretary of State's legal duty to provide listed health services throughout England.

Keywords: UK, England National Health Service (NHS), Health and Social Care (HSC) Act 2012

Copyright: @ 2015 by Kerman University of Medical Sciences

Citation: Pollock AM. Morality and values in support of universal healthcare must be enshrined in law: Comment on "Morality and Markets in the NHS". Int J Health Policy Manag 2015; 4: 399-402. doi: 10.15171/ijhpm.2015.61

\section{Article History:}

Received: 16 February 2015 Accepted: 8 March 2015 ePublished: 12 March 2015

*Correspondence to: Allyson M Pollock Email: a.pollock@qmul.ac.uk
$\mathrm{M}$ orality and values in support of universal healthcare are not ephemeral qualities; if they are to reflect the will and wishes of citizens, they have to be enshrined in law. It was the values of social solidarity that led to the creation of the NHS in 1948 (a desire for and belief in universal healthcare - that they had fought, died in their millions, and expected a better world in return). The alleviation of poverty and want was a political necessity and affordability was achieved by redistribution. The priority was to rebuild the economy and the country by slaying the five giants of inequality: want, ignorance, idleness, disease and squalor - as enunciated in the Beveridge Report. At a time when the country was bankrupted by war, it was decided that the UK would have a welfare state of which the National Health Service (NHS) was a part. These moral values translated into a legal duty on the Secretary of State to provide an NHS throughout the UK.

The moral values of the citizens were thus transformed into a political and legal contract for citizens. The UK NHS was created in 1948 and survived in England until its abolition with the Health and Social Care (HSC) Act 2012. It still survives in Scotland, Wales and Northern Ireland. It remains the most popular and cherished of all the British institutions including the monarchy (2).

There was nothing innovative or moral about the HSC Act 2012 - on the contrary, it was an act of extraordinary savagery and violence against the public in England, and against common values and widely held beliefs in universal healthcare. The coalition government introduced the Bill to abolish the NHS in England without any political mandate, the policy was not trailed in either of the coalition party's manifestos and at no time was there any meaningful consultation with the public. Indeed, David Cameron came to power in 2010, promising in his campaign speeches that there would be no more top down reorganization in the NHS. The Department of Health (DoH) spin machinery and the mainstream media presented the Bill as giving patients more choice and putting General Practitioners (GPs) in charge of health services, and yet the majority of primary care and other doctors including the Royal College of General Practitioners and the BMA opposed it as did the editors of all the major medical journals. At 457-page long the 2012 Act is more than four times the length of the 1946 NHS founding legislation, which was a model of brevity, simplicity and clarity (3).

The abolition of the NHS as a national health service is no exaggeration. It has been accomplished by deleting Sections 1 and 3 of the NHS Act 2006, which placed a legal duty of the Secretary of State to provide listed services throughout England. These listed services include hospitals, mental health services, community services, medical, dental and nursing and hospital services. This legal duty was an obstacle to complete marketisation of funding and break up of delivery; it was a check on the market and on the Secretary of State's power to disregard the will of the people $(4,5)$. 
In the absence of a legal duty to provide these health services, no amount of moralizing or spouting of values on our part can make the government provide health services to all people throughout England. Everything follows and flows from the law; our morality and values have to be enshrined in the law if universal healthcare is to be a reality.

In overturning that legal duty to provide and entrenching market contracting, the government has reduced the NHS to little more than a public funding stream (a government payer, to use the American term) and a logo. In its place is NHS Commissioning Board (NHS England), and its market regulators Monitor and Care Quality Commission, the economic and quality regulators, and new bodies called Clinical Commissioning Groups (CCGs). Americans often describe the NHS as a socialized healthcare system, ignorant of the fact that the NHS was the model maker for so much of the world and for so long. The NHS was not a romantic aspiration, it gave freedom from fear of healthcare bills and denial of care.

The NHS had solid foundations. Its system was based on fairness of funding (income taxes) and designed to maximize redistribution both in distribution of funds (resource allocation) and services. The gross inequities in provision and access that had hitherto existed were remedied over time. The system and services were owned by the public, controlled by the public through the elected government. It was cheap too. An efficient public bureaucracy ensured that administration costs were no more than $5 \%$ of the total budget and costs were contained under 4\% GDP for the first three decades (6). For the first forty years the words purchaser, commissioner, insurer and provider was not part of the NHS lexicon. The system required integrated services and planning for operational purposes and service delivery. There were no providers, only services directly managed by contiguous local area health authorities or boards on behalf of their local populations. The Secretary of State's duty to provide was transmitted through these contiguous area-based structures. There was enormous flexibility, as unlike market contracting there was no lock in, there was the flexibility to change and move services and staff around to meet local needs. The basis of the NHS was built on integration, trust, cooperation and collaboration. There has always been choice in the NHS, the ability to ask for a second and a third opinion. But the government when it introduced its market changes claimed that it was doing so to give patients more choice of providers and to bring in the very small private sector. It used patient choice as the rationale for giving large contracts with a NHS value of around 4 billion pounds to the private sector to undertake elective surgery. The effect was to destabilize NHS services and training and is well-documented in parliamentary enquiries which were highly critical of the policy (7). But the majority of patients want services close by to where they live and of good quality, they do not want to shop around.

Since 1990, market incrementalism has been a hallmark of NHS legislation with the introduction of the purchaser provider split, use of private finance for new capital projects and greater use of the private sector. This required overturning the system of public administration with a market bureaucracy, all under the rubric of managed competition. Commercial contracts took the place of highly efficient systems of public administration and management. The final phase, which is where we are now, is the managed decline of the NHS and its remaining public institutions as the system moves to an American model based not on universalism but residual care based on entitlement or eligibility criteria and mixed funding. Healthcare in England is now being remodeled along U.S. lines where increasingly access will not be through automatic entitlement but through eligibility criteria and determined by the market. The process is well underway for migrants and older people. For the first time since the NHS came into being legislation (Section 103) of the HSC Act requires healthcare providers to draw up eligibility criteria as part of their license conditions. Patients do not choose providers so much as providers must now pick and choose their patients and treatments. Patients can be actively turned away.

In 1990, when the government introduced what is known as the internal market or purchaser provider split, the areabased structures were retained but their power to plan was diminished as services such as hospital and community services were established as corporate bodies or autonomous units. The political motivation was to break the link between the area health authorities and planning and local communities and to encourage competition on the basis of price. For the first time services would be priced requiring an enormous new bureaucracy to support it to create tariffs. In reality, apart from doubling the transaction costs from $6 \%$ to $12 \%$, local area health authorities remained mindful of their legal duty to provide services on the basis of need, ensuring access to high quality local services for all residents remained a priority. The incoming Labour government in 1997 accelerated market driven measures giving new powers to these 'trusts' to raise capital, giving them new financial freedoms to generate private income and greater autonomy not to serve local needs. The link between planned services and the needs of the local population were being broken. Hospitals began to flex their muscles and use their new powers to generate income from private patients and elsewhere, albeit heavily dependent on State subsidy (8). The 2012 legislation now expects that NHS Foundation Trusts (FTs) will generate up to half their income privately so that they will be $51 \%$ public and $49 \%$ private.

The pricing system or tariff which replaces block grants and which are necessary for market contracting are accompanied by the idea that financial incentives and competition are needed to make hospitals, services, doctors and nurses work harder for patients, and so the government spent vast amounts of money putting in place new systems of performance measurement and league tables, including hospital league tables with little or no scientific basis, the balance score card approach comes from industry.

And yet, the evidence from the UK and the U.S. shows that the construction of the tariff is a piece of sorcery, as is its operation. Pricing is a ridiculous notion in a public service - unlike the generics drugs market there is not an infinite number of suppliers to choose from - most areas have only one local hospital and there is no spare capacity in community services. Competition for patients and services simply accelerates closure and destabilizes local money on the 
basis of price leading to inequities in access.

What is moral about a pricing system that incentivizes providers to deny care or that incentivizes them to engage in fraudulent behavior (by upcoding, claiming for treatments they have not given, or gaming to keep their hospital afloat)? Price is what the market can bear or purchasers are prepared to pay it does not reflect the cost (9-11). What is moral about a system where money is wasted by spending $30 \%$ of the budget on transaction costs, lawyers, management consultants and commercial contracting and private finance? What is moral about a pricing system that rewards on the basis of risk selection and not on the basis of need? What is moral about a pricing system that closes hospitals and services in inner city areas because the land costs are so high that they cannot compete by price?

The HSC Act 2012 and the break with the legal duty to provide was accompanied by the dissolution of areabased structures and the installation of a new market bureaucracy reliant on management consultants. The new CCGs structures are not area-based and do not provide for residents in an area rather their membership is drawn from GP practices. GP practice boundaries, once bounded by area authorities, have also been dissolved as of January 2015 and GPs must and can now compete for patients from across England. This membership approach where patients can be drawn from every part of the country is the start of a shift to insurance pools. The old language of integration meant integration between planning and service provision to meet local community needs. Today integration means market integration, horizontal and vertical integration as hospitals and community services merge regardless of the needs and wishes of local communities or planning.

And, at the same time the government is doing all it can to shake our faith in the NHS, that it will be there when we need it. It uses the constant cry of an aging population, lack of affordability or blames the public for inappropriate use of services and rising expectations. All of these are in their own way shibboleths. It is proximity to death not age that determines cost. It is the market that increases the transaction costs and makes healthcare unaffordable. It is services that are contracting, while needs may well be staying constant.

And as for inappropriate use of services, NHS England recently claimed that $40 \%$ of all admissions to $\mathrm{A}$ and $\mathrm{E}$ in England were unnecessary - on the basis that people had been discharged without treatment. The claim was used to justify closure of $\mathrm{A}$ and $\mathrm{E}$ units and reorganization. The president of the Royal College of Emergency Medicine investigated those figures and a subsequent report suggested the figures were incorrect and that fewer than $15 \%$ of these could be seen elsewhere, i.e. in general practice.

The president of the Royal College of Emergency Medicine gave a useful account of $\mathrm{A}$ and $\mathrm{E}$ attendances and admissions that had received no treatment at a public meeting in January. This is what he said: "If I suddenly experience a very bad headache and go to $A$ and $E$, I will have tests and investigations to exclude a subarachnoid haemorrhage. If nothing is found and I recover then I will be discharged. If you turn pale and sweaty and experience sudden acute chest pain you will go to $A$ and $E$ and have an electrocardiogram and troponin levels measured. If it turns out you are well and tests are negative you will return home". To this I can add the experience of one of my students who last week was run over by a motor scooter while crossing the road. She was seen and then discharged with acute swelling of her face and knee and a suspected broken jaw and a fractured patella. Five days later she attended two clinics and examined when the swelling had resolved, her jaw though fractured was stable, as was her knee. She received no treatment for her jaw or her fractured patella. Was this an unnecessary trip to $\mathrm{A}$ and $\mathrm{E}$ and the clinics? Were these all unnecessary visits to $\mathrm{A}$ and $\mathrm{E}$ and the Out patient clinics because they received no treatment? And yet NHS England was putting about figures that $40 \%$ of the 14 million $\mathrm{A}$ and E attendances a year in England were unnecessary, because they receive no treatment. In the UK the family doctor or GP has been the gatekeeper to the service, every day they see patients who need no treatment, reassure them and give them advice that stops them buying quack medicines and reassures anxious mothers and small children, are these trips unnecessary? GPs are being urged on a daily basis not to give unnecessary antibiotics for viruses. The whole point of care is to sift and sort the serious from the non serious and to use our diagnostic skills and to act as gatekeepers to other forms of care and not to provide unnecessary tests and treatment. The government however under the misguided belief that patients are using services unnecessarily is penalizing them by reducing the payments to $\mathrm{A}$ and $\mathrm{E}$ by $30 \%$ to encourage them to turn patients away without being seen.

Politicians declare that, England despite all its wealth declares it can no longer afford universal healthcare although the cost per capita is less than every other country. It certainly cannot afford a market either - the US experience tells us all what is in store if we go down that route, healthcare costs are in excess of $18 \%$ GDP, 60 million are uninsured and another 60 million underinsured and according to the Institute of Medicine (IoM) almost (6\% GDP-750 billion dollars a year) is spent on unnecessary care, administration and the denial of care $(12,13)$.

What is moral about not providing people with the services they need, where is the morality in abdicating responsibility for the provision of healthcare?

Values and morality which underpinned a universal health system cannot be sustained if the law does not require it and if the systems and services are not designed to ensure that it happens. Everything flows from the law. The real question is whether we the public are willing to continue to fight for the reinstatement of our NHS and demand that our politicians have the moral and political courage to do so. Those who say that the NHS Bill will result in more structural reorganisation are correct. But keeping the status quo means de facto endorsing market contracting. It means keeping the disruptive disorganisation which is breaking up the NHS and putting it out to tender. So those who oppose reorganization are content with the market and what they really mean is that they are happy to see the NHS wither away, as is happening now, and for profit corporations to run patient services.

In March a Bill will be tabled in parliament with cross party support which will reinstate the NHS in England by reinstating the duty on the Secretary of State to provide listed services throughout England (http://www.nhsbill2015.org/). Scotland and Wales abolished the internal market and there 
was no chaos. It was done quietly with no disruption. The proposed new NHS (Reinstatement) Bill will abolish market contracting, abolish the expensive market bureaucracy and put back in the structures which are require to meet the needs of local people. A campaign is underway across the UK to reinstate the NHS throughout England. There are demonstrations and marches on a weekly basis demanding that this happens. As the founding father of NHS, Labour Health Minister Aneurin Bevan, famously said: "The NHS will last as long as there are folk left with the faith to fight for it". This May 2015 after the election, we will know whether our politicians have the moral courage to reinstate the NHS as is the case in Scotland and Wales.

\section{Ethical issues}

Not applicable.

Competing interests

Author declares that she has no competing interests.

Author's contribution

AMP is the single author of the manuscript.

\section{References}

1. Gilbert B, Clarke E, Leaver E. Morality and Markets in the NHS. Int J Health Policy Manag 2014; 3: 371-6. doi: 10.15171/ ijhpm.2014.123

2. Katwala S. The NHS: even more cherished than the monarchy and the army [internet]. 14 January, 2013. Available from: http:// www.newstatesman.com/politics/2013/01/nhs-even-morecherished-monarchy-and-army

3. Pollock A, Price D. Duty to care: In defence of universal health care. Centre for Labour and Social Studies; 2013.

4. Pollock A, Price D, Roderick P, Treuherz T. A flawed Bill with a hidden purpose. Lancet 2012; 379: 999. doi: 10.1016/S01406736(12)60246-3

5. Pollock AM, Price D, Roderick P. Health and Social Care Bill 2011: a legal basis for charging and providing fewer health services to people in England. BMJ 2012; 344: e1729. doi: 10.1136/bmj.e1729

6. Webster C. The national health service: A political history. 2nd edition. Oxford: Oxford University Press; 2012.

7. House of Commons. Independent Sector Treatment Centres: Fourth Report of Session 2005-06. London: The Stationery Office Limited; 2006. Available from: http://www.publications. parliament.uk/pa/cm200506/cmselect/cmhealth/934/934i.pdf

8. Pollock AM. NHS plc: The Privatisation of Our Health Care. London: Verso; 2004.

9. Geruso M. Identifying Upcoding in Markets with Adverse Selection: An Application to Medicare. Health \& Healthcare in America: From Economics to Policy; 2014. Available from: https://ashecon.confex.com/ashecon/2014/webprogram/ Paper2138.html

10. Mays N, Dixon A and Jones L. Understanding new labour's market reforms of the English NHS. London: King's Fund; 2011.

11. Pongpirul K. Hospital manipulations in the DRG system: a systematic scoping review. Asian Biomedicine 2013; 7: 301-10.

12. Smith S, Saunders R, Stuckhardt L, McGinnis JM. Best care at lower cost: the path to continuously learning health care in America. Washington, DC: National Academies Press; 2013.

13. Institute of Medicine (IoM). Best Care at Lower Cost: The Path to Continuously Learning Health Care in America [internet]. 2012. Available from: http://www.iom.edu/Reports/2012/Best-Care-atLower-Cost-The-Path-to-Continuously-Learning-Health-Carein-America.aspx 